\title{
Environmental factors influencing fruit production and seed biology of the critically endangered Persoonia pauciflora (Proteaceae)
}

\author{
Nathan J. Emery (D) Catherine A. Offord
}

Published online: 3 June 2019

(C) The Author(s) 2019

\begin{abstract}
The factors that influence seed production and seed dormancy in rare plant species are crucial to their conservation yet are often poorly understood. In this study, we examined the breeding system and seed biology of the critically endangered Australian endemic species Persoonia pauciflora through a series of experiments. Pollinator visitation surveys and manipulative hand-pollination treatments were conducted to investigate the breeding system and subsequent seed production. We used an experimental seed burial to examine the breakdown of the woody endocarp and changes to germination over time. Seed germination response under simulated local seasonal conditions was also examined. Persoonia pauciflora was found to be predominantly pollinated by native bees, and cross-pollinated flowers produced significantly more mature fruit $(18 \pm$ $3 \%)$ than self-pollination treatments (2-3\%). The average strength of $P$. pauciflora pyrenes buried in soil significantly decreased over two years, from $413.3 \pm$ $14.6 \mathrm{~N}$ to $130.8 \pm 11.8 \mathrm{~N}$. Post-burial seed germination was cyclical, with highest final germination percentage occurring following late-summer exhumations $(75 \pm 2 \%$ and $74 \pm 14 \%$, respectively). When seeds were incubated under different local seasonal conditions, germination at local summer temperatures was more likely when compared with autumn/spring and winter temperature-
\end{abstract}

\section{N. J. Emery $(\bowtie) \cdot$ C. A. Offord}

The Australian PlantBank, The Australian Botanic Garden Mount Annan, Royal Botanic Gardens and Domain Trust, Mount Annan, NSW 2567, Australia

e-mail: nathan.emery@rbgsyd.nsw.gov.au incubated seeds. Our study highlights the importance of ensuring appropriate biotic pollen vectors are present in the local landscape for maximising viable fruit production for this species. In addition, our data indicate that recruitment will most likely occur after the endocarp has suitably weakened, allowing physiological dormancy of the embryo to be relaxed and germination to commence following summer temperatures.

Keywords breeding system - endocarp - Leioproctus . Persoonia pauciflora $\cdot$ pollination $\cdot$ seed germination

\section{Introduction}

Numerous factors operating at a range of spatial scales can affect plant abundance or rarity (Schemske et al. 1994). The most important ecological information for conserving rare species is their reproductive traits, as these are associated with species persistence in the landscape. The regeneration niche, originally defined by Grubb (1977), highlights the crucial role of plant reproductive factors for population persistence, with viable seed production noted as a major component of this niche. Important considerations include both species and environmental factors that influence seed production, such as breeding system and pollen vectors. The potential for flow-on effects from seed production means that subsequent factors associated with successful seedling establishment, such as seed dormancy and germination, are also key traits that define the reproductive niche (Grubb 1977; Bykova et al. 2012; Jiménez- 
Alfaro et al. 2016). Seed bank dynamics are a particularly important inclusion in threatened species management, as dormant seeds and adult plants are affected by different suites of external environmental stresses (Pavlik et al. 1993; Donohue et al. 2010). If the requirements for seed germination are ascribed to specific triggers, such as the chemical stimulants in smoke, for example, then populations may become locally extinct in areas where those triggers, such as fires, are not common in the landscape. Indeed, changes in any component of a species' reproductive niche could cause range-shifts through population expansion or extinction, and rare species are likely to be sensitive to even small changes in the reproduction niche (Grubb 1977; Bykova et al. 2012).

The reproductive niche is an especially important consideration for Proteaceae, as species from this expansive plant family often exhibit a very low fruit-to-flower ratio, sometimes as low as $0.01 \%$ (Carolin 1961; Lamont and Barrett 1988). Although numerous contributing factors have been documented (Groom and Lamont 1998), key knowledge gaps remain. The genus Persoonia is endemic to Australia and is a good model in which to study key reproductive traits in Proteaceae, as numerous species have received considerable attention focussed on the mechanisms that affect seed production and germination (Bernhardt and Weston 1996; Weston 2003; Rymer et al. 2005; Chia et al. 2016b; Emery and Offord 2018). Several species are known to have breeding systems that preferentially select outcrossed pollen (Krauss 1994; Cadzow and Carthew 2000; Wallace et al. 2002; Rymer et al. 2005). For example, Krauss (1994) reported $20 \%$ of outcrossed flowers from $P$. mollis plants produced mature fruit, compared with only $1 \%$ of self-pollinated flowers. Fruit set was also very high in $P$. rigida when flowers were left open to outcrossing (67.4\%; Trueman and Wallace 1999). This could not be matched by manual crosspollination, suggesting that manual hand-pollination does not effectively mimic natural pollinator behaviour to achieve similar pollination success (Trueman and Wallace 1999). Leioproctus (sub-genus Cladocerapis) bees are widely reported to be frequent visitors to eastern Australian Persoonia species (Bernhardt and Weston 1996; Wallace et al. 2002; Rymer et al. 2005). When foraging on Persoonia flowers, Leioproctus bees contact the stigma as they collect pollen and nectar, making them effective pollinators of the genus (M. Batley pers. comm.).

Persoonia fruits contain a woody endocarp, which is noted as a mechanical dormancy mechanism in the genus, and germination only occurs if the endocarp is at least partially removed (Bauer et al. 2004; Chia et al. 2016b). Within the endocarp is one or two seeds, comprising an outer testa that holds an embryo and cotyledons. Some Persoonia species have a physiologically dormant embryo that requires specific environmental cues (i.e. temperature and moisture) for germination (Bauer and Johnston 1999). Furthermore, if physiological dormancy is alleviated, the embryo must then have enough growth potential to break through the endocarp (Nikolaeva 1969). In an ecological context, the window of conditions required for relaxing physiological dormancy in the embryo should reflect the local climate, meaning that variation in germination may be apparent at fine scales (JiménezAlfaro et al. 2016). This intricate relationship between the endocarp and embryo suggests that Persoonia germination traits - and the seed biology more generally should be examined in both laboratory and field environments (Baskin et al. 2006; Emery and Offord 2018).

Seed burial trialling is a common method to examine the effects of dormancy over time. This is because the initial age and viability of the seeds are known, allowing the effects of the environment on dormancy release and germination to be interrogated. For example, following a two-year soil burial, Norman and Koch (2008) found P. longifolia endocarps did not significantly decline in hardness, and still required chipping to stimulate germination. More recently, Chia et al. (2016b) reported the germination of exhumed $P$. longifolia seeds was cyclical, and highest following 30 months of burial. It was determined that the combination of endocarp weakening caused by significant wet/dry cycles, coupled with warm summer temperatures breaking physiological dormancy, allowed seeds to subsequently germinate (Chia et al. 2016b). Temperature, in particular, has a pivotal role in controlling physiological dormancy, as many species require a period of constant temperatures within a threshold, or the correct alternating temperature pattern for relaxing dormancy (Offord and Meagher 2001). Additionally, this temperature window varies according to the species and the geographic distribution of its populations. Thompson et al. (1977) illustrated this by screening 292 plants for the alternating temperature and light regimes in which germination was promoted. The authors noted that the response of species to ex situ conditions reflected the conditions experienced in situ. In this way, species could be grouped according to habitat (Thompson et al. 1977). In a comprehensive study on 43 species in Western Australia, Bell et al. (1995) demonstrated that the relationship between 
germination and temperature was dependent on a species' life history, and suggested that understorey species were likely to have more specific germination requirements compared to overstorey species.

With nine species currently threatened, endangered or critically endangered, there are important conservation outcomes for understanding the link between the environment and seed traits in Persoonia (Rymer et al. 2005; Nield et al. 2015; Chia et al. 2016a, b; Emery et al. 2018). Of the 99 known Persoonia species, P. pauciflora P.H.Weston is the only critically endangered species currently listed under both the Australian Environment Protection and Biodiversity Conservation Act 1999 and the New South Wales (NSW) Biodiversity Conservation Act 2016. Persoonia pauciflora has a highly restricted distribution within the Broad-leaved
Ironbark (Eucalyptus fibrosa) and Spotted Gum (Corymbia maculata) woodlands around North Rothbury in the lower Hunter Valley region of NSW (Fig. 1). Spatially, the species encompasses a linear range of $4.3 \mathrm{~km}$, a total area of occupancy of 29 ha, and around two-thirds of the plants occur on a single private property (Office of Environment and Heritage 2012). Persoonia pauciflora is a small, spreading shrub that grows between $0.1-1.4 \mathrm{~m}$ high and $0.4-1.6 \mathrm{~m}$ wide, and occurs on the silty sandstone soils derived from the geological Farley formation (Weston 1999). Flowers comprise four yellow recurved tepals that range between 4.5-8.0 mm long, four stamens, and a single gynoecium containing one ovule that produces a fleshy, drupaceous fruit (Fig. 2; Weston 1999). Peak flowering is from December to May; however, as is typical of this genus,

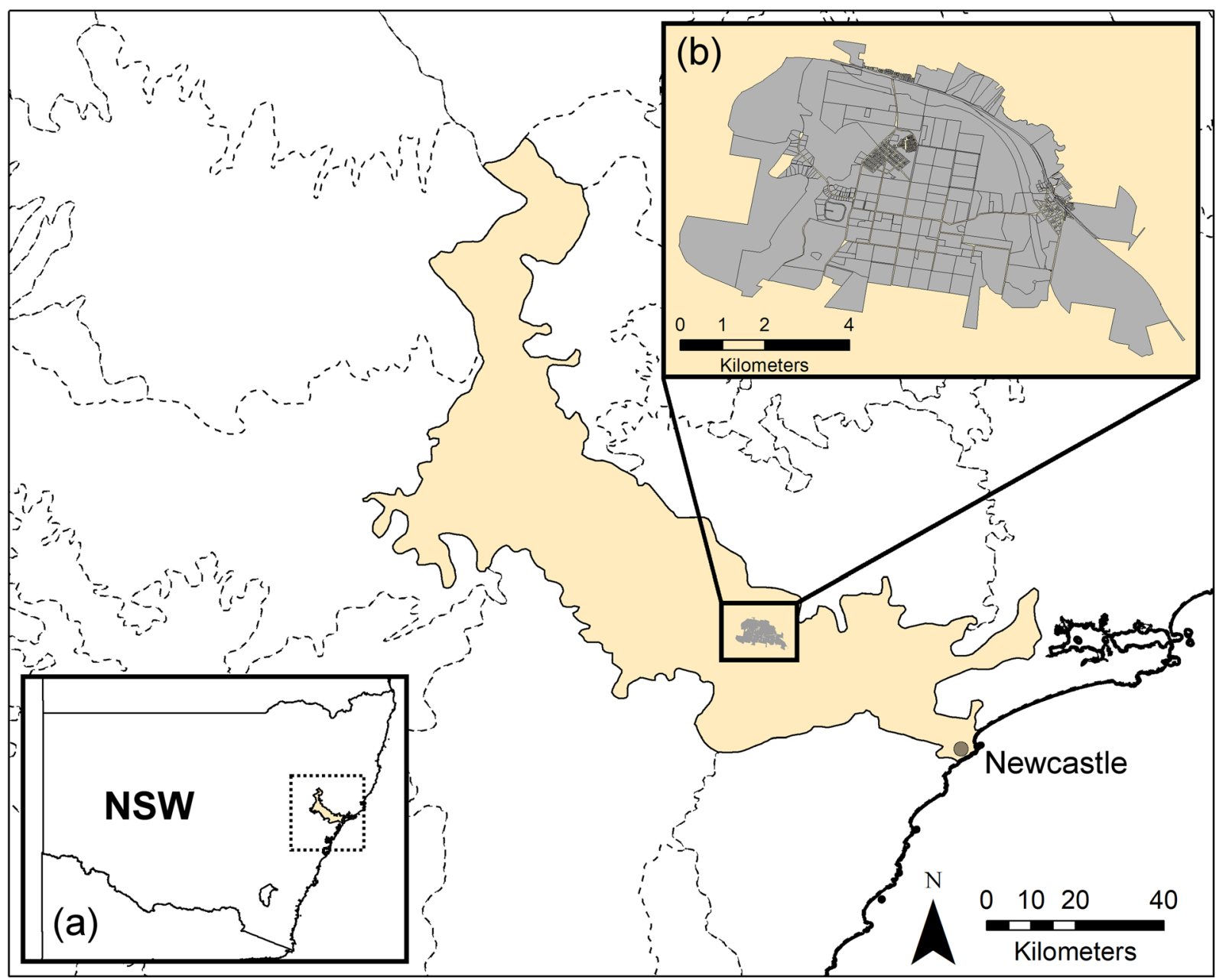

Fig. 1 Map showing the approximate spatial distribution of Persoonia pauciflora. The species is confined to the town of North Rothbury and surrounds (b), situated in the Hunter bioregion of
NSW (a) approximately $50 \mathrm{~km} \mathrm{WNW} \mathrm{of} \mathrm{Newcastle.} \mathrm{Plant} \mathrm{records}$ are not shown due to the species threatened status 

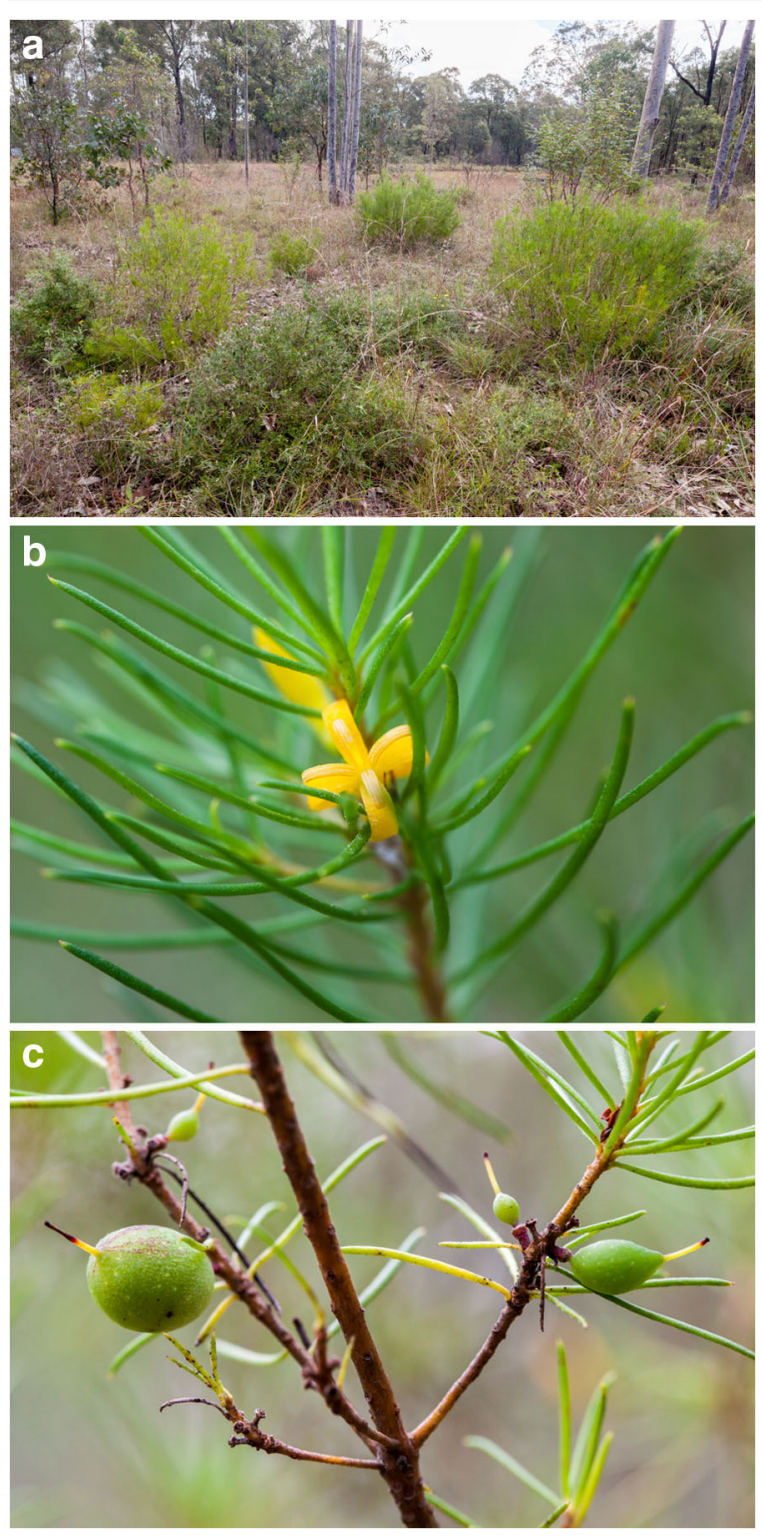

Fig. 2 a-Persoonia pauciflora is an erect spreading shrub with lime-green foliage. $\mathbf{b}$ - The small, inconspicuous yellow flowers are characterized by four yellow recurved tepals, four stamens, and a single gynoecium. $\mathbf{c}$ - Each pollinated ovule slowly matures into a green fleshy fruit. Photos: N. Emery

flowering can also occur randomly throughout the year. Persoonia pauciflora does not appear to have a lignotuber (present in some Persoonia species), relying solely on recruitment in the soil seedbank. The species is currently threatened by habitat fragmentation and loss due to urban development. Several P. pauciflora seedlings have been observed in the wild, but little is known of its reproductive niche.
In this study, we performed a series of experiments that each examined a component of the reproductive niche of $P$. pauciflora, specifically focused towards factors that might influence seed production and germination traits. The aims of this study were to: (1) investigate the visitation rates of native and exotic pollinators, (2) assess the level of self-compatibility and its impact on seed production, (3) determine the rate of endocarp breakdown and how seed germination changes following soil burial, and (4) examine the seasonal temperature regime in which seeds are most likely to germinate. Several experimental translocations of $P$. pauciflora, including population supplementation and assisted colonization, have recently occurred (Emery et al. 2018). The data from the present study can be used to help determine and monitor translocation outcomes. More broadly, this study provides a model for other rare flora for investigating the reproduction niche and its potential impact on persistence in the landscape.

\section{Materials and methods}

\section{Study sites}

Pollinator visitation was surveyed on the largest natural population of $P$. pauciflora, occurring on a private property in North Rothbury, NSW, located in the approximate centre of the species distribution (termed Site 1). Approximately 600 plants have been surveyed to occur on the property. We collected fruits from plants on the property in October 2015 and again in October 2016. Since fruits are only mature when dropped from the maternal plants, only recently dropped fruits found on the ground below plants were collected (Catelotti and Offord 2017). Fruits were also collected in October 2016 from another property that has the second-largest population surveyed (around 200 plants; termed Site 2). We buried pyrenes (i.e. endocarp and seed within; flesh cleaned and removed) on a conservation offset land in North Rothbury (termed Site 3). This site had several extant plants and was previously used for an experimental conservation planting. Hand-pollination treatments to investigate the breeding system were conducted at the Australian Botanic Garden Mount Annan (ABGMA) using a potted collection of 88 plants. These plants were propagated using plant material collected in 2009 from the same population that was surveyed for pollinator visitation in this study. The potting medium used to 
grow the propagated plants comprised crushed quartz and coir fibre.

\section{Pollinator visitation experiment}

Thirty-four randomly selected P. pauciflora plants were tagged within a $60 \mathrm{~m}^{2}$ area where the study species density was deemed to be highest. Tagged plants encompassed different ages, and above ground plant height ranged from 45 to $125 \mathrm{~cm}$ (average $79.1 \pm 3.2$ ) and the number of flowering branches per plant during surveys ranged from 2 to 323 (average $93.3 \pm 12.2$ ). Surveys were conducted over five days during November and December 2015. Tagged plants were randomly observed for pollinator visitation for $10 \mathrm{~min}$ each, between 08:00 $\mathrm{h}$ and 17:00 $\mathrm{h}$ each day. A pollinator was recorded if it was observed gathering pollen or nectar from a flower. To determine pollinator effort, the number of flowers visited per plant before the insect flew away from the plant was also recorded. Visitor species identities were recorded and classified as native or exotic species (i.e. European honeybees), and examples of any unidentified species in the field were caught and taken back to the laboratory for identification.

Data for pollinator abundance and pollinator effort showed a Poisson distribution and analyses were conducted as generalized linear mixed models using the lme 4 package (Bates et al. 2018) in R (v. 3.4.0). Survey days and plants were included as random effects and bee type (native bee or honeybee) as a fixed effect in both models.

\section{Breeding system}

To assess the degree of self-compatibility of P. pauciflora, we randomly tagged 30 plants from the potted collection at ABGMA for hand-pollination treatments in November 2015. These plants were grown in a low organic, high drainage soil mix containing crushed quartz and coir fibre. All tagged plants were reproductively mature and were $47 \pm 10.2 \mathrm{~cm}$ tall on average, spaced $30-50 \mathrm{~cm}$ apart and watered daily. From the available flowering branches, we randomly selected four branches per plant and assigned each of the four branches to one of the following pollination treatments:

(i) Closed/autogamy: the branch was bagged prior to flower opening and not manipulated further; (ii) Self: branches were bagged prior to flowering. As flowers opened, pollen from dehisced anthers was collected and brushed against the stigma of the same flower;

(iii) Geitonogamy: branches were bagged prior to flowering. As flowers opened, self-pollen was removed and stigmas were brushed with pollen collected from at least five flowers on different nonbagged branches of the same plant; and

(iv) Crossed/xenogamy: flowers were treated the same as (iii) except that flowers were brushed with pollen collected from at least five flowers from a genetically different plant.

The number of flowers on each tagged branch was counted prior to any treatment. Any flowers that had already opened or senesced on tagged branches were not counted. Stigmas were receptive prior to any manual pollination treatment (i.e. sticky glistening stigmatic surface). Pollinators were excluded using large organza bags with a mesh size sufficient to exclude visitors while allowing air and moisture to pass through. Fruit set was recorded in February 2016, determined as the number of swollen ovaries on a tagged branch. The number of fruits maturing on tagged branches was recorded in August 2016, where fruit maturation was defined as the presence of a green, fleshy drupe with purple spots or striations visible on the pericarp. Each fruit was cut in half using secateurs and the presence of a viable seed was recorded when the white embryo was visible.

The effect of pollination treatment on fruit set and fruit maturation was analysed separately. Fruit set and maturation proportional data were log-transformed to satisfy assumptions of normal distribution prior to analysis in $R$ (version 3.4.0). We used a two-factor linear model to determine if there were significant differences between the number of fruits on branches and recorded data for fruit set or maturation. We investigated pairwise comparisons between treatments using a post-hoc Tukey's HSD test where applicable.

\section{Seed burial experiment}

To examine the rate of endocarp breakdown in the soil, we buried 600 three-month old pyrenes at Site 3 . At the burial site, six $0.5 \times 2 \mathrm{~m}$ plots were established adjacent to one another. Each plot had four replicate sets of 25 pyrenes that were buried under $2-5 \mathrm{~cm}$ of soil. For each 
replicate, pyrenes were mixed with local soil and sealed in organza mesh bags $(90 \times 120 \mathrm{~mm})$, and then bags were buried in the soil using metal pegs to mark their locations. Pyrenes were buried at the end of summer, in February 2016, and exhumed at six-monthly intervals over 24 months, until February 2018. One bag per plot was exhumed at each interval to retrieve a total of 150 pyrenes. A further 150 fresh pyrenes (i.e. 0 months burial) were also tested in February 2016 as below.

Following exhumation, the six replicate pyrenes bags were bulked and cleaned of soil using sieves and brushes in the laboratory at ABGMA. Twenty-five pyrenes were randomly chosen for assessing endocarp strength via penetrometer force (N), using an Enpaix Digital Force Gauge (EFG1000 and manual test stand; SI Instruments, South Australia). A pyrene was placed longitudinally on a flat metal surface and cracked using a flat metal probe attached to the penetrometer. The peak force required to crack the endocarp was recorded for each pyrene.

Mean pyrene weight was assessed by weighing a further 25 exhumed pyrenes chosen at random. The permeability to water was measured by then soaking pyrenes in deionized water for $30 \mathrm{~h}$. During this time course, the pyrenes were removed from the water at 0.5 , $1,2,4,8,24$ and $30 \mathrm{~h}$ time points, then lightly dried and weighed. The percentage increase in seed mass per time interval was calculated as the mean imbibed weight divided by the mean non-imbibed weight. Following imbibition, endocarp strength was tested on pyrenes using the EFG1000 as outlined above.

The remaining 100 pyrenes were used for germination testing. Pyrenes were soaked in deionized water overnight to soften the endocarps. A mounted hand vice was used to extract seeds from the endocarps, and seeds were transferred to a weak bleach solution (1-2\%) for 15 min to help minimize microbial contamination during incubation. Bleach-treated seeds were then transferred into deionized water and soaked for a further $15 \mathrm{~min}$. Seeds were sown on water agar plates $(0.7 \%$ $w / v)$ in replicates of 25 and incubated at a $10 / 25^{\circ} \mathrm{C}$ temperature regime with a $12 \mathrm{~h} / 12 \mathrm{~h}$ light/dark photoperiod for ten weeks. Seeds with a visible radicle of $>2 \mathrm{~mm}$ were scored as germinated, and then removed.

General linear models were used to examine changes to pyrene strength and the proportion of germination over the two-year burial period. Final germination was adjusted following viability checks of non-germinated seeds. Seeds with a firm, white embryo were scored as viable following the ten-week germination period.
Variables with significant differences were then analysed using a Tukey HSD post-hoc test. The data were analysed in $\mathrm{R}$ (v. 3.4.0).

Simulated seasonal germination experiment

To examine the effect of temperature on germination probability, we collected approximately 1,800 fruits from approximately 40-50 plants at each of Site 1 and Site 2 in September 2016. The outer fleshy layers of the fruits were removed, and the remaining pyrenes were cleaned in the laboratory at ABGMA. Seeds were extracted from endocarps as described for the seed burial study. A factorial treatment combination of two collections sites and three incubation temperature regimes was applied. The factorial design was replicated on both water agar $(0.7 \% \mathrm{w} / \mathrm{v})$ and agar containing the germination stimulant gibberellic acid $\left(\mathrm{GA}_{3}\right.$ agar), which has been shown to increase germination success in some Persoonia species (Nancarrow 2001; Mullins et al. 2002)

For each treatment combination, a total of 96 seeds were sown into sterile plastic cell culture plates with 24 flat-bottom wells (Corning® Costar® TC-treated; 3.4 $\mathrm{mL}$ well capacity). Each well contained approximately 2 $\mathrm{mL}$ of agar, and one seed was sown per well. Well-plates were used over traditional petri plates due to their ability to isolate seeds and, therefore, any possible fungal contamination. $\mathrm{GA}_{3}$ agar was prepared as per water agar, but with $250 \mathrm{ppm}$ gibberellic acid powder dissolved into the molten agar immediately prior to pouring. Seeds were incubated for ten weeks at one of three different alternating temperature regimes that reflected seasonal averages in North Rothbury between 2014 and 2016. These were: (1) $5 / 18^{\circ} \mathrm{C}$ (winter), (2) $10 / 25^{\circ} \mathrm{C}$ (autumn and spring; but hereafter referred to as 'autumn'), or (3) 18/29 ${ }^{\circ} \mathrm{C}$ (summer; Cessnock Airport, Australian Weather Station; www.bom.gov.au). Plates were checked on a weekly basis and seeds with a protruding radicle of $>2 \mathrm{~mm}$ were recorded as germinated.

Germination on both agar treatments was recorded as a weekly count for each plate replicate and then analysed using a linear model to examine the interactive effects of incubation temperature and site. We used weekly germination checks as a repeating measure in the models. Post-hoc tests using Tukey's HSD were run where necessary to identify significant differences. Time-to-event models were performed to analyse the germination rate $\left(\mathrm{g}_{\mathrm{r}}\right)$ and time to $50 \%$ germination $\left(\mathrm{T}_{50}\right)$, relative to the maximum germination among 
experiment treatment combinations. These regression models take into consideration that a seed may have germinated at any point within a survey interval (Ritz et al. 2013). Furthermore, the model assumes that nongerminated viable seeds at the end of the experiment may still germinate if the experiment was to continue (i.e. right-censored data). The data were analysed in $\mathrm{R}$ (version 3.4.0), with the time-to-event models analysed using the 'drc' R package (Ritz et al. 2016).

\section{Results}

Pollinator visitation

During the five days of surveys, 55 European Honeybees (Apis mellifera) and 270 native bees (including Leioproctus incanescens, L. speculiferus, Amegilla sp. and Tetragonula carbonaria) were recorded on P. pauciflora flowers. Leioproctus species accounted for around $95 \%$ of native bee observations. There was a significant difference in the total number of honeybees compared to native bees across the survey period $(P<$ 0.001; Fig. 3). There were few instances of high bee abundance on plants over the five survey days $(<15 \%$ of observations). Although there was a 5:1 ratio of native bees to honeybees, they displayed similar foraging

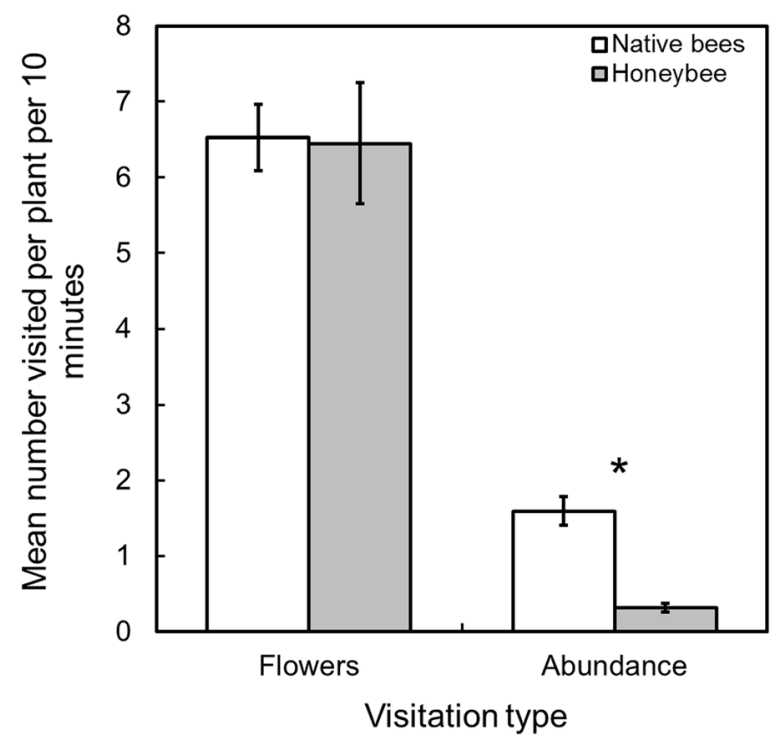

Fig. 3 The mean $( \pm S E)$ number native bees, honeybees and the mean number of flowers visited per Persoonia pauciflora plant (per 10-min observation). An asterisk (*) denotes a significant difference between native bees and honeybees from the generalized linear mixed model efforts $(P=0.06$; Fig. 3$)$. Native bees foraged on an average of $6.53 \pm 0.44$ flowers per plant per ten minutes before moving to an adjacent plant, while honeybees foraged on an average of $6.45 \pm 0.80$ flowers. Foraging effort was similar among the survey days and plants.

\section{Breeding system}

Due to inclement weather and damage to tags, data for the breeding system assessments were obtained from 27 plants rather than the original 30 . The number of flowers per branch ranged among pollination treatments from 21 \pm 2 to $29 \pm 2$, which did not represent a significant variation $(P=0.113)$. Self-compatibility was observed in the species, as fruit set occurred in autogamy $(9 \pm 2 \%)$, self $(8 \pm 2 \%)$ and geitonogamy $(11 \pm 5 \%)$ treatments (Fig. 4). By contrast, $23 \pm 5 \%$ of xenogamously pollinated flowers had set fruit, which was significantly higher than all other treatments $(P=0.003$; Fig. 4$)$. A similar pattern was observed for the number of fruits maturing per branch, with xenogamously treated branches exhibiting significantly higher values $(18 \pm 3 \%)$ than the remaining three treatments, which ranged from $2 \pm 1 \%$ to $3 \pm 1 \%$ $(P<0.001$; Fig. 4). At the time of recording fruit maturation, the number of fruits on tagged branches was significantly lower across treatments compared to when fruit set was recorded $(P=0.001)$.

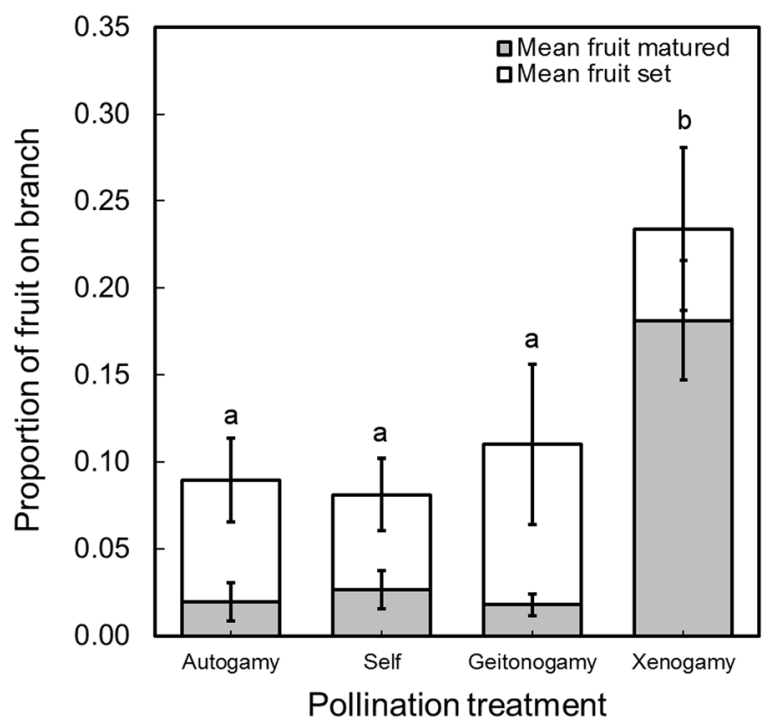

Fig. 4 Average percentage of fruits on tagged branches of Persoonia pauciflora plants $(n=27)$ across pollination treatments. Different lower-case letters indicate significant a difference in percent fruit set and percent fruits matured between treatments 
Seed burial

The average strength of dry P. pauciflora pyrenes buried in soil significantly decreased over time from $413.3 \pm 14.6 \mathrm{~N}$ to $130.8 \pm 11.8 \mathrm{~N}(P<0.001$; Fig. 5a). Of the $68 \%$ decrease in pyrene strength after a two-year burial, $42 \%$ of this decline occurred during the first six months. Pyrene strength following imbibition also significantly decreased from $304.7 \pm 10.6 \mathrm{~N}$ to $84.5 \pm 8.8 \mathrm{~N}$ after two years of soil burial $(P<0.001)$. Imbibing fresh pyrenes resulted in a $26.3 \%$ decrease in endocarp strength compared to the dry endocarp strength. Endocarp fracturing was visible after twelve months of burial; however, no in situ germination was observed. Fresh pyrenes had an average dry weight of $160 \pm 4 \mathrm{mg}$, which declined to $110 \pm 5 \mathrm{mg}$ after 12 months in the soil (i.e. $68 \%$ of the average dry weight of fresh pyrenes), and then remained stable over the second 12 months in the soil (Fig. 5b). Fresh pyrenes had an average weight increase of $42 \%$ (from $160 \pm 4 \mathrm{mg}$ to $228 \pm 7 \mathrm{mg}$ ) following $30 \mathrm{~h}$ of imbibition, whereas water uptake for pyrenes buried for 6-24 months was lower (8-28\% weight increase; Fig. 5 b). Water uptake by fresh pyrenes was greatest in the first $8 \mathrm{~h}$ and plateaued thereafter. Across all burial durations (6-24 months), water uptake was greatest between 8 and $24 \mathrm{~h}$ before plateauing at $30 \mathrm{~h}$ (Fig. 5b).

The ex situ germination percentage of fresh seeds was $13 \pm 3 \%$. Germination of exhumed P. pauciflora seeds occurred from all burial intervals, with the seed batches displaying a seasonal, cyclic germination throughout the two-year burial period (Fig. 5c). Percent germination was similar between the two winterexhumed seed batches ( $26 \pm 4 \%$ for 6 months, and 26 $\pm 6 \%$ for 18 months). No significant difference was detected between the germination of fresh seeds and seeds buried for 6 months $(P=0.244)$ or 18 months

Fig. 5 a - Penetrometer force $(N \pm S E)$ required to crack Persoonia pauciflora pyrenes following soil burial over two years. Pyrenes were cracked when dry (open circles) and following $30 \mathrm{~h}$ water imbibition (grey circles). b - Average weight $( \pm S E$ ) of $P$. pauciflora pyrenes measured after imbibing water for $0,0.5,1,2,4,6,8,24$ and $30 \mathrm{~h}$ following soil burial for up to two years. c - Final germination percentage $( \pm S E)$ of P. pauciflora seeds sown on water agar and incubated at $10 / 25^{\circ} \mathrm{C}$ following soil burial over two years, and adjusted for viability
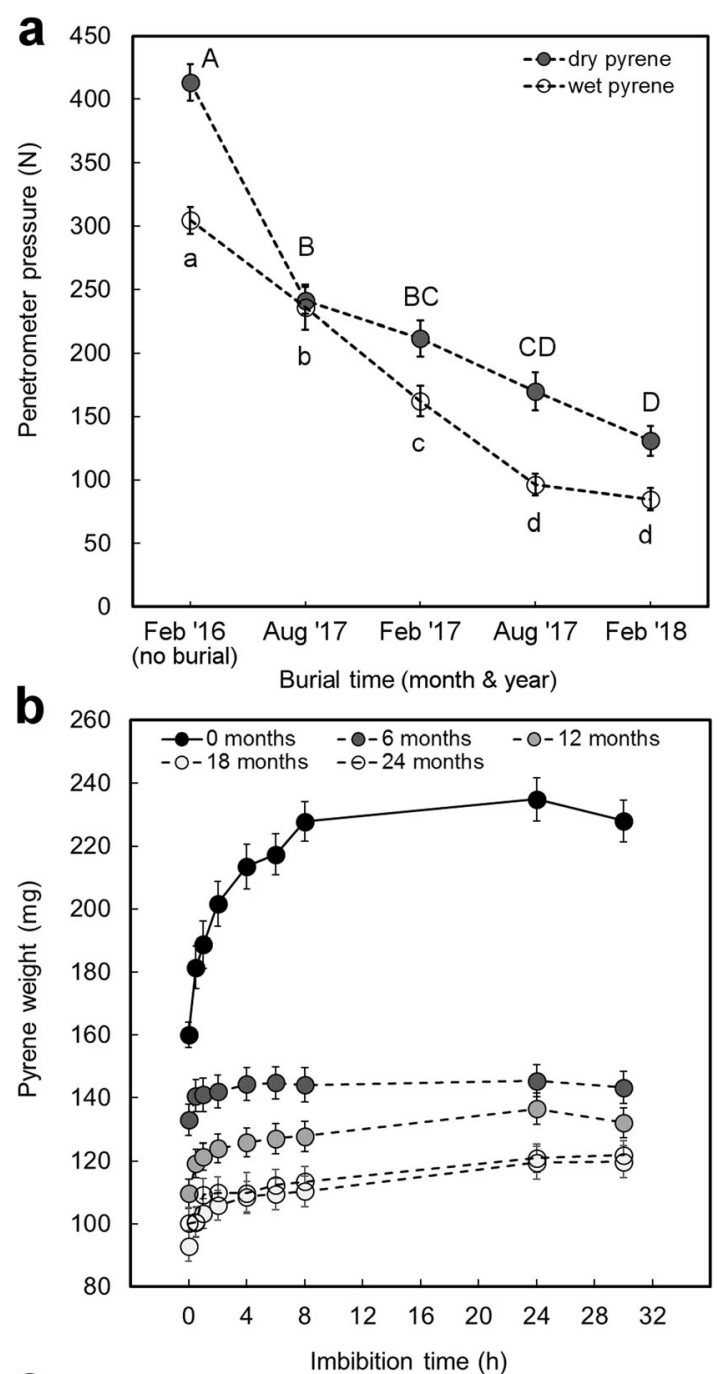

C

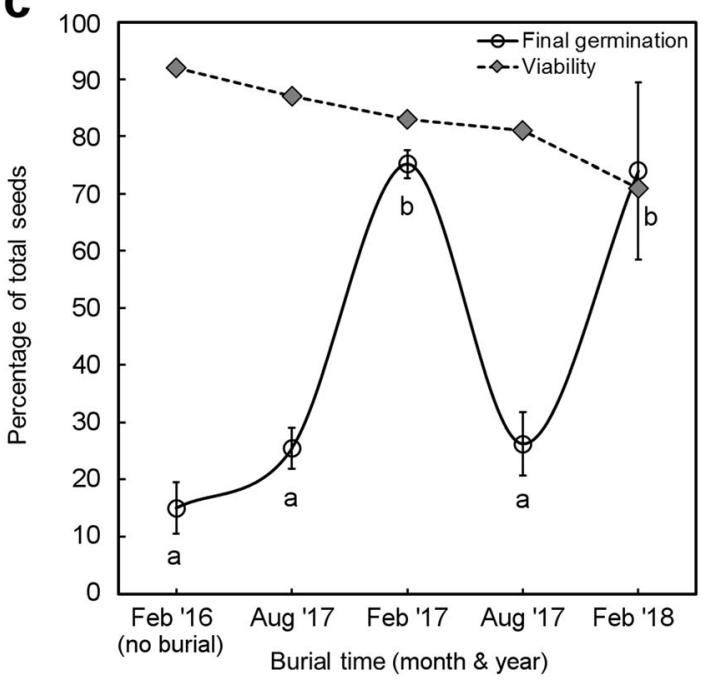


$(P=0.214)$. Compared to fresh seeds, percent germination significantly increased following summerexhumations at 12 and 24 months $(75 \pm 2 \%$ and $74 \pm$ $14 \%$, respectively; both $P<0.001)$. The initial viability of fresh seeds was $92 \%$, which declined to $71 \%$ over two years of burial in the soil (Fig. 5c).

Simulated seasonal germination

The germination of P. pauciflora seeds on water agar was highly variable across seasonal temperature regimes and sites, with a significant interaction identified between temperature and site $(P<0.001)$. The highest germination percentage on water agar was exhibited by seeds collected from Site 1 and incubated under the autumn temperature regime ( $51 \pm 4 \%$; Fig. 6$)$. By comparison, the lowest germination percentage on water agar occurred for seeds collected from Site 2 and incubated under the winter temperature regime $(4 \pm 2 \%$; Fig. 6). Germination on water agar was significantly lower for both study sites when seeds were incubated at winter temperatures $(P<0.001)$. Germination was more consistent among the temperature regimes and site when seeds were sown on $\mathrm{GA}_{3}$ agar, varying between $15 \pm 6 \%$ and $25 \pm 5 \%$ (Fig. 6). A significant interaction between site and temperature was concluded from the linear model $(P=0.001)$, with germination percentage increasing on $\mathrm{GA}_{3}$ agar compared to water agar for seeds collected from Site 2, while the converse was true Site 1 seeds.

Seeds germinated on water agar at the winter temperature had a significantly slower $\mathrm{g}_{\mathrm{r}}$ than those germinated at summer and autumn temperatures for both study sites $(P<0.001$ and $P=0.009$, respectively). Seeds from Site 2 had a significantly higher $\mathrm{g}_{\mathrm{r}}$ on water agar under the summer temperature regime than the autumn temperature regime $(P=0.042)$. By comparison, for Site 1 seeds the $g_{\mathrm{r}}$ was statistically similar when incubated at summer and autumn temperature regimes $(P=0.868$; Table 1$) . \mathrm{T}_{50}$ was significantly slower when seeds from either site were incubated at the winter temperature regime on water agar, compared to the summer and autumn regimes. There was no significant difference in $\mathrm{T}_{50}$ detected between the summer and autumn temperature regimes for either site (Table 1). On $\mathrm{GA}_{3}$ agar, $\mathrm{g}_{\mathrm{r}}$ and $\mathrm{T}_{50}$ were each statistically similar across the three temperature regimes and two Sites (Table 1).

\section{Discussion}

Pollinator visitation

Our results showed that Persoonia panciflora is predominantly visited by native bees. Leioproctus incanescens and L. speculiferus were the most common visitors recorded during surveys, with peak visitation in the morning. These native bees are solitary foragers and have anatomical features, including a flattened clypeus and spines on the basitarsi of females, that make them specialist pollen and nectar gatherers from Persoonia flowers (Rayment 1950; Maynard 1992; Wallace et al. 2002). Leioproctus do not solely visit Persoonia, having previously been recorded on plants such as Leptospermum sp., Lomatia silaifolia and Claoxylon australe (Maynard 1992). Both male and female Leioproctus are known to forage on Persoonia flowers (Maynard 1992), and this was found to be the case for P. pauciflora plants with both sexes recorded in our surveys. Studies have recorded L. incanescens and L. speculiferus as visitors of up to eight and twelve eastern Australian Persoonia species, respectively (Bernhardt and Weston 1996; Wallace et al. 2002). Leioproctus species have also been documented to visit rare and common sub-species of $P$. mollis (Rymer et al. 2005). Though Bernhardt and Weston (1996) noted that Exoneura sp. frequently visit Persoonia, we did not record these bees in our surveys. Further seasonal surveys would help determine whether other native bee species visit $P$. pauciflora flowers.

Honeybees were also commonly observed visiting P. pauciflora flowers. Pollinator observations of several endangered Persoonia species, including P. bargoensis, $P$. mollis subsp. maxima and $P$. glaucescens, found honeybees to be the dominant floral visitor (Field et al. 2005; Rymer et al. 2005). However, honeybees may be less efficient pollinators than Leioproctus bees, as occasionally honeybees do not pollinate flowers since they tend to mix the nectar and pollen together on their bodies, causing pollen grains to germinate prematurely (Paton 1997). Although significantly less abundant than native bees, honeybees foraging effort on $P$. pauciflora flowers was statistically similar to native bees. Several population factors are also known to influence pollinator presence and foraging behaviour, including plant density, abundance, floral display size and their interactions (Field et al. 2005). For example, within-plant foraging efforts of pollinators were significantly higher in a low- 

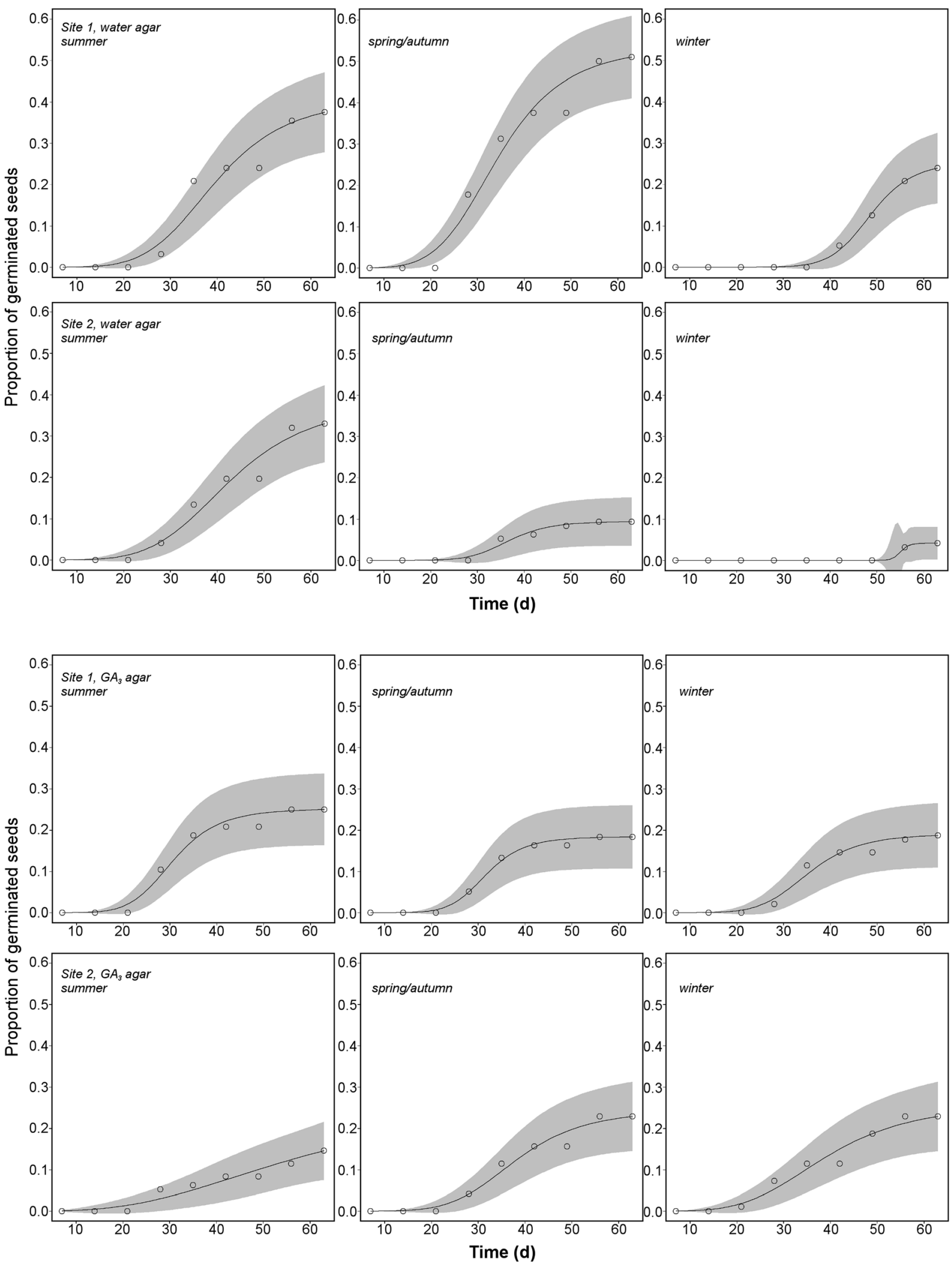
Fig. 6 Observed proportion of germinated Persoonia pauciflora seeds relative to the total from two sites under three season temperature regimes and two agar mediums using time-to-event models. Weekly germination totals are represented by points and shaded areas represent $95 \%$ CIs

density $P$. bargoensis population when compared with a high-density population (Field et al. 2005). Such specificity in observing chiefly Leioproctus species in our study could be an indication of the extremely narrow geographic distribution of $P$. pauciflora, low plant abundance and density, a lack of diversity of bees in the local area, or only a subset of local bees are attracted to P. pauciflora. Furthermore, it is possible that Leioproctus species often co-occur in habitats where Persoonia species are present. Since $P$. linearis co-occurs with P. pauciflora, these habitats may then be more attractive to Leioproctus bees due to a higher abundance of flowers. However, it is also unlikely that Persoonia species rely solely on Leioproctus species, as other bees including Tetragonula, Xylocopa, Exoneura and Apis, have been recorded visiting flowers (Bernhardt and Weston 1996; Wallace et al. 2002; Rymer et al. 2005).

\section{Breeding system}

Our results indicate that $P$. pauciflora has a selfcompatible breeding system; however, the species is a preferential out-crosser, as xenogamously pollinated flowers produced significantly more fruit than any other pollination treatment. Self-compatibility is thought to be an evolutionary strategy of rare plants to ensure some level of reproductive success when pollinators are limited (Kunin and Gaston 1993). Typical of Proteaceae, P. pauciflora was found to have a very low fruit-toflower ratio, and the cross-pollinated fruit set was comparatively lower than other previously studied Persoonia species (Carolin 1961; Trueman and Wallace 1999; Wallace et al. 2002; Rymer et al. 2005). Furthermore, the fact that significantly fewer fruits remained on branches compared to the number of recorded mature fruit could indicate a possible post-zygotic mechanism that terminates self-pollinated fruit. This mechanism was originally identified in Persoonia by Krauss (1994), who noted selfed fruit to be terminated on $P$. mollis plants between 4 and 30 weeks post-pollination. A low number of matured fruits could also be a factor of rarity and inbreeding. In common with our study, two other endangered species, $P$. glaucescens and $P$. mollis subsp. maxi$m a$, both produced mature fruits in only less than $20 \%$ of out-crossed flowers (Rymer et al. 2005).

\section{Seed burial}

Pyrene burial within the Broad-leaved Ironbark and Spotted Gum woodland distribution of P. pauciflora resulted in the gradual degradation of the endocarp and cyclical germination over the two years. The average strength of $P$. pauciflora endocarps declined by around $40 \%$ following six months of soil burial, and by almost

Table 1 Germination of Persoonia pauciflora seeds from two sites incubated under three seasonal temperature regimes

\begin{tabular}{|c|c|c|c|c|c|}
\hline & & Germination temperature & $g_{\text {final }}[\%]$ & $T_{50}[$ days $]$ & $g_{\mathrm{r}}[$ slope $]$ \\
\hline \multirow[t]{6}{*}{ Water agar } & \multirow[t]{3}{*}{ Site 1} & Summer $\left(18 / 29^{\circ} \mathrm{C}\right)$ & $38 \pm 6^{\mathrm{a}}$ & $39.6 \pm 3.0^{\mathrm{a}}$ & $-5.0 \pm 0.9^{\mathrm{a}}$ \\
\hline & & Autumn $\left(10 / 25^{\circ} \mathrm{C}\right)$ & $51 \pm 4^{\mathrm{b}}$ & $34.5 \pm 2.1^{\mathrm{a}}$ & $-4.8 \pm 0.7^{\mathrm{a}}$ \\
\hline & & Winter $\left(5 / 18^{\circ} \mathrm{C}\right)$ & $24 \pm 5^{\mathrm{c}}$ & $48.7 \pm 1.9^{b}$ & $-10.9 \pm 2.6^{b}$ \\
\hline & \multirow[t]{3}{*}{ Site 2} & Summer $\left(18 / 29^{\circ} \mathrm{C}\right)$ & $33 \pm 3^{\mathrm{ac}}$ & $42.7 \pm 4.0^{\mathrm{a}}$ & $-4.8 \pm 1.0^{\mathrm{a}}$ \\
\hline & & Autumn $\left(10 / 25^{\circ} \mathrm{C}\right)$ & $9 \pm 1^{d}$ & $36.6 \pm 2.7^{\mathrm{a}}$ & $-8.4 \pm 2.7^{b}$ \\
\hline & & Winter $\left(5 / 18^{\circ} \mathrm{C}\right)$ & $4 \pm 2^{d}$ & $55.1 \pm 2.5^{b}$ & $-65.1 \pm 166.7^{\mathrm{c}}$ \\
\hline \multirow[t]{6}{*}{$\mathrm{GA}_{3}$ agar } & \multirow[t]{3}{*}{ Site 1} & Summer $\left(18 / 29^{\circ} \mathrm{C}\right)$ & $25 \pm 5^{\mathrm{a}}$ & $30.7 \pm 1.8^{\mathrm{a}}$ & $-6.3 \pm 1.3^{\mathrm{a}}$ \\
\hline & & Autumn $\left(10 / 25^{\circ} \mathrm{C}\right)$ & $18 \pm 2^{a b}$ & $31.7 \pm 1.7^{\mathrm{a}}$ & $-7.8 \pm 1.8^{\mathrm{a}}$ \\
\hline & & Winter $\left(5 / 18^{\circ} \mathrm{C}\right)$ & $19 \pm 3^{b}$ & $35.3 \pm 2.4^{\mathrm{a}}$ & $-6.5 \pm 1.6^{\mathrm{a}}$ \\
\hline & \multirow[t]{3}{*}{ Site 2} & Summer $\left(18 / 29^{\circ} \mathrm{C}\right)$ & $15 \pm 6^{b}$ & $57.8 \pm 33.7^{\mathrm{a}}$ & $-2.8 \pm 1.2^{\mathrm{a}}$ \\
\hline & & Autumn $\left(10 / 25^{\circ} \mathrm{C}\right)$ & $23 \pm 4^{\mathrm{ab}}$ & $38.1 \pm 3.3^{\mathrm{a}}$ & $-5.2 \pm 1.2^{\mathrm{a}}$ \\
\hline & & Winter $\left(5 / 18^{\circ} \mathrm{C}\right)$ & $23 \pm 4^{b}$ & $39.0 \pm 4.7^{\mathrm{a}}$ & $-4.1 \pm 1.0^{\mathrm{a}}$ \\
\hline
\end{tabular}

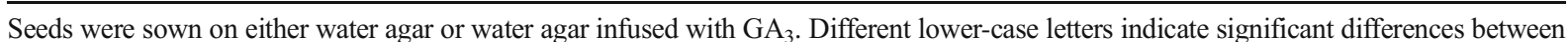
site and germination temperature treatments. Each agar medium was analysed separately 


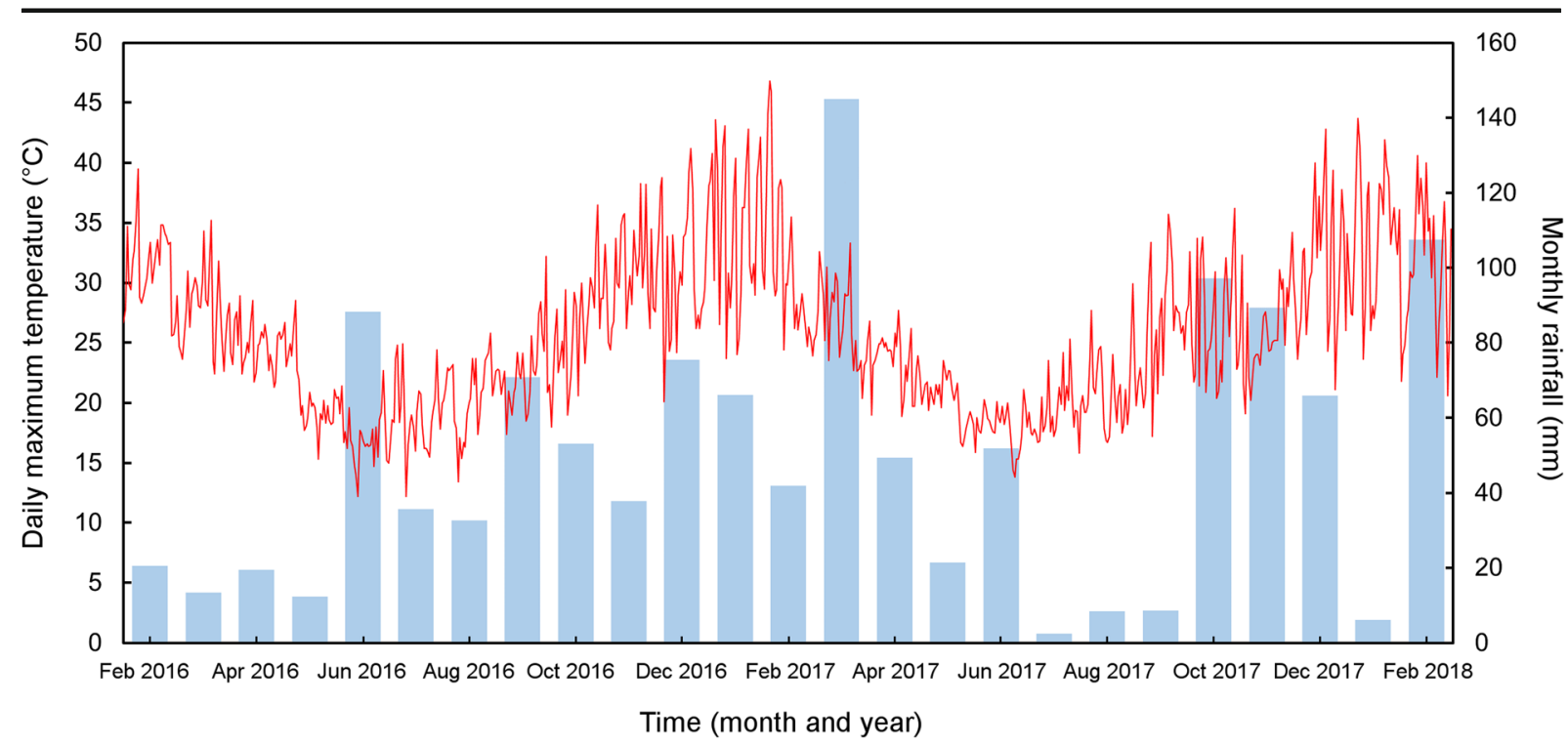

Fig. 7 Daily maximum temperature $\left({ }^{\circ} \mathrm{C}\right)$ and monthly rainfall $(\mathrm{mm})$ over the two years of the soil burial experiment. Climate data was recorded from the Cessnock Australian Weather Station and downloaded from the Bureau of Meteorology website (www.bom.gov.au)

$70 \%$ following two years of soil burial. Pyrenes also began imbibing within the first hour of soaking, confirming that the endocarp is water-permeable. Although natural fracture lines on buried endocarps were visible by 12 months, no in situ germination was observed throughout the burial time (N. Emery pers. obs.). In contrast to our results, in a study of $P$. longifolia there was no significant change in the strength of endocarps following two years soil burial (Norman and Koch 2008). This difference in endocarp degradation between these two species might be attributed to the fact that the fresh $P$. longifolia endocarps reported by Norman and Koch (2008) were around $150 \%$ stronger than fresh P. pauciflora endocarps (around $600 \mathrm{~N}$ and $400 \mathrm{~N}$, respectively). The rate of in situ endocarp degradation and subsequent germination is also directly influenced by seasonal climate and local site factors (Chia et al. 2016a, b).

Maximum germination percentage occurred following late-summer exhumation at 12 and 24 months burial (February 2017 and 2018; 75\% and 74\%, respectively). For $P$. longifolia seeds, an increase in germination success to $40 \%$ has been reported following 8 months burial; but these seeds required endocarp chipping, $\mathrm{GA}_{3}$ and smoke-water treatments to promote germination (Mullins et al. 2002). Similarly, chipped and $\mathrm{GA}_{3}$ treated $P$. longifolia seeds germinated to $37 \%$ following 21 months burial in the soil in another trial (Norman and Koch 2008). When P. longifolia endocarps were buried for three years under field and nursery conditions, germination reached $64 \%$ and $42 \%$, respectively (Chia et al. 2016b). These results suggested the endocarp was the main barrier to germination. Persoonia virgata and $P$. sericea also required at least half of the endocarp to be removed for seeds to germinate, with chipping being insufficient for germination to occur (Ketelhohn et al. 1996; Bauer et al. 2004). Here, in the absence of the endocarp, P. pauciflora germination significantly varied throughout the soil burial trial, indicating that dormancy was not solely caused by the endocarp. That germination percentage was significantly higher following retrieval from the soil in late summer (12 and 24 months) compared to winter retrieval (6 and 18 months) suggests that the $P$. pauciflora embryos exhibited cyclical physiological dormancy. Summer conditions during the seed burial experiment were hotter and drier when compared to the local long-term average $\left(29.6^{\circ} \mathrm{C}\right.$ and $256.6 \mathrm{~mm}$ rainfall over summer). Around $180 \mathrm{~mm}$ of rain occurred over both summer seasons during the seed burial experiment and coupled with hot summer maximum temperatures $\left(32.5 \pm 0.4^{\circ} \mathrm{C}\right.$ daily average during experiment) may have provided suitable environmental conditions to relax physiological dormancy (Fig. 7). However, it is possible that an initial period of cool winter temperatures was also required to relax physiological dormancy (i.e. cold stratification). Future burial trials should aim to exhume pyrenes monthly to ascertain whether both cold and warm temperatures relax 
dormancy. Cyclical germination has also been reported in buried P. longifolia seeds, with significantly higher germination occurring following autumn retrieval compared with late winter or early spring retrieval (Chia et al. 2016b).

Coupled with the cyclical germination and decline in endocarp strength, viability of fresh $P$. pauciflora seeds was $92 \%$ and steadily declined to $71 \%$ over two years of soil burial. This confirms that $P$. pauciflora has the potential to form an accumulating soil seed bank. The observed decline in seed viability over time resulted in an increased prevalence of microbial contamination of incubated seeds. Mixed results of long-term persistence of seeds in the soil seed bank have been reported in several Persoonia species. In two separate studies on P. longifolia, one found no significant loss of viability following two years soil burial, and the other a decline in viability from $93 \%$ to $68 \%$ after three years soil burial (Norman and Koch 2008; Chia et al. 2016b). Persoonia pinifolia seeds were estimated to exhibit an average decline in viability of $50 \%$ after one year in the soil (Auld et al. 2007). The potential for seeds to survive this timeframe is partially determined by the local ambient conditions. For example, P. longifolia seeds have been noted to rapidly lose viability when stored at $4{ }^{\circ} \mathrm{C}$ (Mullins et al. 2002). A significant decline in viability of $P$. mollis subsp. nectens buried seeds was also recorded following a burn (McKenna 2007).

\section{Seasonal germination}

Germinating P. pauciflora seeds under different seasonal temperature regimes - simulating those occurring in its natural locality - suggested that germination is most likely to occur during summer, following the relaxing of physiological dormancy with warmer temperatures. However, seeds from different local sites showed variation in the width of their temperature window, with seeds from Site 1 having a greater potential to also readily germinate when conditions are cooler in autumn and spring. The capacity to germinate extracted Persoonia seeds has been met with mixed success (McIntyre 1969; Bauer and Johnston 1999; Nancarrow 2001; Mullins et al. 2002; Bauer et al. 2004). As many studies have approached germinating Persoonia with a horticultural impetus, few have described the temperature conditions required for germination in Persoonia. In a seasonal field trial, $P$. longifolia germination was reported to occur during the transition from winter to spring (August to September) in south-west Western Australia (Chia et al. 2015). When P. longifolia seeds were incubated under ex situ winter temperatures, germination was reported to be highest at $20^{\circ} \mathrm{C}$, or under a $10 / 20^{\circ} \mathrm{C}$ cycle (Chia et al. 2016b). Micro-site variation may explain the wider temperature window for the germination of P. pauciflora seeds from Site 1 compared to seeds from Site 2.

The physiological dormancy mechanism imposed by the embryo may also be species-specific or vary among years and population cohorts depending on conditions during fruit maturation on the maternal plant. The use of $\mathrm{GA}_{3}$ has been demonstrated to alleviate physiological dormancy and increase germination success in several Persoonia (Ketelhohn et al. 1996; Nancarrow 2001; Mullins et al. 2002; Bauer et al. 2004). In our study, $\mathrm{GA}_{3}$ elicited similar germination responses among sites and temperature regimes. When compared with germination on water agar, overall germination was either reduced or increased on $\mathrm{GA}_{3}$ agar. This complex germination response might be explained by a combination of the increased microbial contamination of seeds observed on the $\mathrm{GA}_{3}$ agar, and a varying degree of receptivity of Persoonia seeds to $\mathrm{GA}_{3}$. For example, in a comparative germination study, $P$. levis germination was positively affected by $\mathrm{GA}_{3}$, whereas $P$. myrtilloides seeds had no response (Nancarrow 2001). Microbial contamination has been reported to negatively affect the germination of numerous Persoonia species since initial trials by McIntyre (1969), and is one of the main limitations of ex situ germination experiments. Despite our best efforts to surface sterilize seeds, contamination in our experiment was most prevalent on $\mathrm{GA}_{3}$ agar and often originated from within the seed, indicating endogenous microbes were still present. Microbial growth could be promoted by $\mathrm{GA}_{3}$ as similar chemical derivatives have a microbial origin (Brian et al. 1954).

\section{Conclusions}

The set of experiments presented here encompass several components of the reproductive niche of Persoonia pauciflora. Biotic and abiotic factors can influence the reproductive niche at multiple developmental stages from flower development and seed production to seed dormancy and germination. Indeed, reproductive traits are often more sensitive to changes in external 
conditions than other vegetative traits (Snider and Oosterhuis 2011). These complex mechanisms make studies on the reproductive niche of vital importance, particularly in rare species, as these traits will ultimately define population persistence and overall species distributions (Bykova et al. 2012). Other external environmental factors not examined in this study, such as soil microsite factors that vary over time, could also ultimately determine seedling establishment.

For this critically endangered species, a partially selfcompatible breeding system means that viable fruits should be seasonally produced, as some fruits may still reach full maturity in the absence of pollinators. We have demonstrated that a cross-pollination mechanism produced significantly greater numbers of fruit, which is important as plants with a self-compatible breeding system that are incapable of out-crossing without a biotic vector to transfer pollen are at the greatest risk of inbreeding depression. Local bee species, in particular Leioproctus spp. that were observed as floral visitors in a natural population, may then form an important interaction with $P$. pauciflora to increase the likelihood of cross-pollination and, therefore, a larger and more genetically diverse fruit cohort. Following fruit drop, the environmental conditions are then critical for breaking dormancy and controlling germination. The woody endocarp is a mechanical barrier that restricts germination and must suitably weaken over time to permit embryo growth. Coupled with the slow decline in seed viability, there is potential for an accumulating seed bank to form while endocarps weaken in the soil. A second set of environmental parameters are then required to relax physiological dormancy within the embryo, and summer temperature conditions were found to be important for regulating this trait. Similarly, germination was more likely to occur when seeds were exposed to warmer local temperatures. Overall, the insights from this study into the ecological interactions and mechanisms with seed production, dormancy and germination that define the reproductive niche will play a vital role in the development of future propagation, restoration and management policies for P. pauciflora and other related species.

Acknowledgements The authors wish to thank Fraser and Margaret Green for allowing us to conduct field observations on their property. We thank Nick Colman, Charles Foster and Luana Lins for helping to survey floral visitors. We also thank Veronica Viler for assistance in looking after the plants in the nursery. Finally, we thank Michael Batley at the Australian Museum, Sydney for identifying Leioproctus bees to species. This work forms part of the conservation research program for Persoonia pauciflora funded through the Office of Environment and Heritage, Newcastle. Karen Sommerville and Christie Foster provided helpful comments and feedback on an earlier version of this manuscript.

\section{Compliance with ethical standards}

Conflict of interest The authors declare no conflict of interest with the experiments in this study. Fruit collections were made according to NSW Scientific licence conditions (SL100569).

Open Access This article is distributed under the terms of the Creative Commons Attribution 4.0 International License (http:// creativecommons.org/licenses/by/4.0/), which permits unrestricted use, distribution, and reproduction in any medium, provided you give appropriate credit to the original author(s) and the source, provide a link to the Creative Commons license, and indicate if changes were made.

\section{References}

Auld TD, Denham AJ, Turner K (2007) Dispersal and recruitment dynamics in the fleshy-fruited Persoonia lanceolata (Proteaceae). J Veg Sci 18:903-910

Baskin CC, Thompson K, Baskin JM (2006) Mistakes in germination ecology and how to avoid them. Seed Sci Res 16:165-168

Bates D, Maechler M, Bolker B, Walker S, Christensen RHB, Singmann H, Dai B, Scheipl F, Grothendieck G, Green P, Fox J (2018). Package 'Ime4'. Available at https://cran.r-project. org/web/packages/lme4/lme4.pdf Accessed 24 Jan 2019

Bauer LM, Johnston M (1999) Propagation of Persoonia virgata for the development of a new floricultural export crop. The University of Queensland, Queensland

Bauer LM, Johnston ME, Williams RR (2004) Fruit processing, seed viability and dormancy mechanisms of Persoonia sericea A. Cunn. ex R. Br. and P. virgata R. Br. (Proteaceae). Seed Sci Technol 32:663-670

Bell DT, Rokich DP, McChesney CJ, Plummer JA (1995) Effects of temperature, light and gibberellic acid on the germination of seeds of 43 species native to Western Australia. J Veg Sci 6:797-806

Bernhardt P, Weston P (1996) The pollination ecology of Persoonia (Proteaceae) in eastern Australia. Telopea 6:775-804

Brian P, Elson G, Hemming H, Radley M (1954) The plantgrowth-promoting properties of gibberellic acid, a metabolic product of the fungus Gibberella fujikuroi. J Sci Food Agric 5:602-612

Bykova O, Chuine I, Morin X, Higgins SI (2012) Temperature dependence of the reproduction niche and its relevance for plant species distributions. J Biogeogr 39:2191-2200

Cadzow B, Carthew SM (2000) Breeding system and fruit development in Persoonia juniperina (Proteaceae). Cunninghamia 6:941-950

Carolin R (1961) Pollination of the Proteaceae. Austral Mus Mag 13:371-374

Catelotti KA, Offord CA (2017) Managing and conserving native plant species in the mining environment - seed germination 
biology and alternative ex situ storage of Persoonia germplasm for restoration. Report prepared for The Australian Coal Association Research Program. Sydney, Australia

Chia K, Koch J, Sadler R, Turner S (2015) Developmental phenology of Persoonia longifolia (Proteaceae, R. Br.) and the impact of fire on these events. Austral J Bot 63:415-425

Chia KA, Koch JM, Sadler R, Turner SR (2016a) Re-establishing the mid-storey tree Persoonia longifolia (Proteaceae) in restored forest following bauxite mining in southern Western Australia. Ecol Res 31:627-638

Chia KA, Sadler R, Turner SR, Baskin CC (2016b) Identification of the seasonal conditions required for dormancy break of Persoonia longifolia (Proteaceae), a species with a woody indehiscent endocarp. Ann Bot (Oxford) 118:331-346

Donohue K, Casas KK, Burghart L, Kovach LK, Willis CG (2010) Germination, post germination adaptation, and species ecological ranges. Annual Rev Ecol Evol Syst 41:293-319

Emery NJ, Hillier P, Offord CA (2018) Threatened plant translocation case study: Persoonia pauciflora (North Rothbury Persoonia), Proteaceae. Australas Pl Conservation 26:18-21

Emery NJ, Offord CA (2018) Managing Persoonia (Proteaceae) species in the landscape through a better understanding of their seed biology and ecology. Cunninghamia 18:89-107

Field DL, Ayre DJ, Whelan RJ (2005) The effect of local plant density on pollinator behavior and the breeding system of Persoonia bargoensis (Proteaceae). Int J Pl Sci 166:969-977

Groom PK, Lamont BB (1998) Seed and seedling biology of the woody-fruited Proteaceae. Austral J Bot 46:387-406

Grubb PJ (1977) The maintenance of species-richness in plant communities: the importance of the regeneration niche. Biol Rev 52:107-145

Jiménez-Alfaro B, Silveira FA, Fidelis A, Poschlod P, Commander LE (2016) Seed germination traits can contribute better to plant community ecology. $J$ Veg Sci 27:637-645

Ketelhohn LM, Johnston ME, Williams RR (1996) Propagation of Persoonia virgata for commercial development. In Considine J, Gibbs J (eds) Third International Symposium on New Floricultural Crops. Perth, WA, pp 157-164

Krauss SL (1994) Preferential outcrossing in the complex species Persoonia mollis R. Br. (Proteaceae). Oecologia 97:256-264

Kunin WE, Gaston KJ (1993) The biology of rarity: patterns, causes and consequences. Trends Ecol Evol 8:298-301

Lamont BB, Barrett GJ (1988) Constraints on seed production and storage in a root-suckering Banksia. J Ecol 76:1069-1082

Maynard G (1992) Revision of Leioproctus (Cladocerapis) Cockerell (Hymenoptera: Colletidae). Austral J Entomol 31:1-11

McIntyre DK (1969) The germination of dormant Persoonia pinifolia $R$. Br. seeds by the use of gibberellic acid. Canberra Botanical Gardens Report, ACT 69/6

McKenna DJ (2007) Demographic and ecological indicators of rarity in a suite of obligate-seeding Persoonia (Proteaceae) shrubs. PhD thesis, Biological Sciences, University of Wollongong, NSW

Mullins RG, Koch JM, Ward SC (2002) Practical method of germination for a key jarrah forest species: Snottygobble (Persoonia longifolia). Ecol Managem Restorat 3:97-103

Nancarrow CD (2001) Germination of Persoonia myrtilloides and P. levis. In Combined Proceedings International Plant Propagators Society, pp 166-170

Nield AP, Monaco S, Birnbaum C, Enright NJ (2015) Regeneration failure threatens persistence of Persoonia elliptica (Proteaceae) in Western Australian jarrah forests. Pl Ecol 216:189-198

Nikolaeva MG (1969) Physiology of deep dormancy in seeds. Israel Program for Scientific Translations, Jerusalem

Norman MA, Koch JM (2008) The effect of in situ seed burial on dormancy break in three woody-fruited species (Ericaceae and Proteaceae) endemic to Western Australia. Austral J Bot 56:493-500

Office of Environment and Heritage (2012) National recovery plan: North Rothbury Persoonia Persoonia pauciflora. Office of Environment and Heritage

Offord CA, Meagher PF (2001) Effects of temperature, light and stratification on seed germination of Wollemi pine (Wollemia nobilis, Araucariaceae). Austral J Bot 49:699-704

Paton DC (1997) Honey bees Apis mellifera and the disruption of plant-pollinator systems in Australia. Vict Naturalist 114:23-29

Pavlik BM, Ferguson N, Nelson M (1993) Assessing limitations on the growth of endangered plant populations, II. Seed production and seed bank dynamics of Erysimum capitatum ssp. angustatum and Oenothera deltoides ssp. howellii. Biol Conservation 65:267-278

Rayment T (1950) New bees and wasps - Part xiv. Three new bees in the genus Cladocerapis, and their role in the pollination of several Persoonia species ('Geebungs'). Victoria Naturalist 67:101-111

Ritz C, Pipper CB, Streibig JC (2013) Analysis of germination data from agricultural experiments. Eur J Agron 45:1-6

Ritz C, Strebig JC, Ritz MC (2016). Package 'drc'. Available at https://cran.r-project.org/web/packages/drc/drc.pdf Accessed 8 Nov 2017

Rymer PD, Whelan RJ, Ayre DJ, Weston PH, Russell KG (2005) Reproductive success and pollinator effectiveness differ in common and rare Persoonia species (Proteaceae). Biol Conservation 123:521-532

Schemske DW, Husband BC, Ruckelshaus MH, Goodwillie C, Parker IM, Bishop JG (1994) Evaluating approaches to the conservation of rare and endangered plants. Ecology 75:584 606

Snider JL, Oosterhuis DM (2011) How does timing, duration, and severity of heat stress influence pollen-pistil interactions in angiosperms? Pl Signaling Behav 6:930-933

Thompson K, Grime J, Mason G (1977) Seed germination in response to diurnal fluctuations of temperature. Nature 267: 147-149

Trueman S, Wallace H (1999) Pollination and resource constraints on fruit set and fruit size of Persoonia rigida (Proteaceae). Ann Bot (Oxford) 83:145-155

Wallace HM, Maynard GV, Trueman SJ (2002) Insect flower visitors, foraging behaviour and their effectiveness as pollinators of Persoonia virgata R. Br. (Proteaceae). Austral J Entomol 41:55-59

Weston P (1999) Persoonia pauciflora (Proteaceae), a new species from the Hunter Valley. Telopea 8:159-164

Weston P (2003) Proteaceae subfamily Persoonioideae. Botany of the Geebungs, Snottygobbles and their relatives. Austral Pl 22:62-78

Publisher's note Springer Nature remains neutral with regard to jurisdictional claims in published maps and institutional affiliations. 